Hydrology and Earth System Sciences, 8(5), 861-876 (2004) C EGU

\title{
Defining environmental river flow requirements - a review
}

\author{
Mike Acreman and Michael J Dunbar \\ Centre for Ecology and Hydrology, Wallingford, Oxon., OX10 8BB, UK \\ Email of corresponding author: man@ceh.ac.uk
}

\begin{abstract}
Around the world, there is an increasing desire, supported by national and regional policies and legislation, to conserve or restore the ecological health and functioning of rivers and their associated wetlands for human use and biodiversity. To achieve this, many organisations have developed methods for defining "environmental flows", i.e. the flow regime required in a river to achieve desired ecological objectives. This paper reviews the various methods available and suggests a simple categorisation of the methods into four types: look-up tables, desktop analysis; functional analysis and hydraulic habitat modelling. No method is necessarily better than another; each may be suitable for different applications. Whilst look-up methods are easy and cheap to apply, they can be expensive to develop, are less accurate and more suitable for scoping studies; in contrast, although hydraulic habitat modelling is more expensive to apply, it is suitable for impact assessment at specific sites. Each method would need to be used within a wider decision-support framework. These are generally either objective-based to define a target flow regime for a specific desired river status, or scenario-based to indicate the relative merits of various flow regime options for the river environment.
\end{abstract}

Keywords: environmental flow, instream flow, river habitat modelling, building block method, flow scenario analysis, objective setting.

\section{Introduction}

The Earth Summit in Rio de Janeiro in 1992 promoted the conservation of ecosystems as a public good, independent of their utility as a resource. A logical extension to this is to grant water rights to species and ecosystems, alongside the rights demanded by mankind. The work of Costanza et al. (1997) and Postel and Carpenter (1997) has highlighted the enormous economic importance of ecosystem functions and services to mankind. The role of sustainable water resources management in ensuring the integrity of ecosystems was highlighted in the declaration from the Second World Water Forum in The Hague in 2000. Finally, the 2002 Johannesburg World Summit on Sustainable Development reinforced the role of environmental protection as a key pillar of sustainable development. Many countries, such as South Africa (Rowlston and Palmer, 2002) and more recently Tanzania (Ministry of Water and Livestock Development, 2002) have developed laws and policies that give priority of water to river ecosystems once basic human needs are met. International organisations, such as The World Conservation Union (IUCN) are now promoting environmental flow as a key element of integrated water resources management (Dyson et al., 2003). This recognises that functioning ecosystems are important for millions of rural poor people who live off natural resources as well as for the world's biodiversity.

Various factors determine the health of a river ecosystem (Norris and Thoms, 1999). These include discharge (flow), the physical structure of the channel and riparian zone, water quality, channel management such as macrophyte cutting and dredging, level of exploitation (e.g. fishing) and the presence of physical barriers to connectivity. Current status of the science of hydro-ecology that links hydrology and freshwater ecology is described in recent texts (Dunbar and Acreman, 2001, and references therein; Postel and Richter, 2003). This paper focuses on applying this knowledge to determine the quantity or volume of water, through time, required to maintain river health in a particular state. This state may be pre-determined or agreed based on a trade-off with other considerations. It has been given various names, including the environmental flow (regime), instream flow, environmental allocation or ecological flow requirement. These are distinct from terms such as compensation flows 
(Gustard et al., 1987), which have been set for other purposes, such as downstream human uses (e.g. irrigation, hydropower), pollutant dilution or navigation. However, in practice, a particular flow 'in' a river will serve multiple functions.

The first environmental flows were focused on the concept of a minimum flow level; based on the idea that all river health problems are associated with low flows and that, as long as the flow is kept at or above a critical level, the river ecosystem will be conserved. However, it is increasingly recognised that all elements of a flow regime, including floods, medium and low flows are important (Poff et al., 1997; Hill and Beschta, 1991; Junk et al.,1989). Thus, any changes in the flow regime will influence the river ecosystem in some way. Consequently, if the aim is to maintain a pristine natural river ecosystem, the environmental flow will have to be very close to the natural flow regime. However, most river ecosystems are managed to a greater or lesser extent for human requirements; removal of water from the river, such as for public water supply, irrigation and industrial processing, may well be essential for mankind's survival and development. In some cases, water is returned to the river after use (this use is termed non-consumptive) such as hydropower generation or cooling of industrial plant. In the case of run-of-river hydropower, there may be little effect on flows, although upstream water velocities may be affected and the scheme itself could interrupt river connectivity. If water is diverted for hydropower, the timing of flows downstream of the point where water is returned is likely to be altered, and flows will be depleted in a bypassed section. In other cases, such as abstraction for irrigation, waste water may be returned in such small quantities or so far away from the abstraction point that it can be considered, effectively, to have been consumed. The challenge for river scientists is to help decision makers predict the consequences of varying degrees of alteration of the flow regime so that the implications for society are understood; in return, society must clarify the goals for river management so that river scientists can determine appropriate flow recommendations. The move to restore flow regimes that mimic natural variability marks the evolution of a new river management paradigm (Postel and Richter, 2003; Poff et al., 1997).

Since the mid-1970s, methods have been developed to define just what the environmental flow for a given river should be (Wesche and Rechard, 1985; Reiser, 1989; Dunbar et al., 1998; Tharme, 2003; Acreman and King 2003). Each method has advantages and disadvantages which make it suitable for a particular set of circumstances. Criteria for method selection include the type of issue (abstraction, dam, run-of-river scheme), the management objective (e.g. pristine or working river), expertise, time and money available and the legislative framework within which the flows must be set.

This paper describes the types of methods and frameworks used in different parts of the world to determine environmental flows. Also, a priori objective-based approaches have been contrasted with those based on comparison of alternative scenarios.

\section{Objective-based versus scenario- based flow setting}

No simple figure can be given for the environmental flow requirement of rivers; it is related to a number of factors, including:

- the size of the river;

- its natural state, 'type' or perceived sensitivity;

- a combination of the desired state of the river and, in practice, the uses to which it is put.

Consequently, before defining flow requirements, broader objectives must be determined to indicate the type of river desired.

For some river systems, river flows are set to achieve specific pre-defined ecological, economic or social objectives. This is called objective-based flow setting. For example, the objective for the central valley of the Senegal River basin has been to maintain an area of 50000 hectares of floodplain for flood recession agriculture. As approximately half the flooded area is cultivated, this equates to inundation of 100000 hectares, which requires around 7500 million $\mathrm{m}^{3}$ of water to be released from Manantali dam in the head waters (Acreman, 2003). As a further example, the Water Framework Directive of the European Union (European Commission and Parliament, 2000) requires that a reference status is defined for all rivers (as well as lakes, estuaries and coastal areas). The definition of the reference state requires there to be an assemblage of component species that would be found in an 'undisturbed' state. In turn, 'high status' allows only minor deviation from this condition. The Directive requires member states to achieve 'Good Status' (GS) in all surface and ground waters. Good Status is a combination of Good Chemical Status and Good Ecological Status (GES). GES is defined qualitatively as slight deviation from the reference status, based on populations and communities of fish, macro-invertebrates, macrophytes and phytobenthos, and phytoplankton. It also includes supporting elements which will affect the biological elements such as channel form, water depth and river flow. Setting appropriate environmental flows is a key step in achieving Good Status. In South Africa, a river classification 
is also used; however, rather than aiming for good status in all cases, the Department of Water Affairs and Forestry sets objectives, according to different ecological management targets (Rogers and Bestbier, 1997). There are four target classes, A-D (Table 1). Two additional classes, E and F may describe the present ecological status but cannot be a target. Water resources currently in category $\mathrm{E}$ or $\mathrm{F}$ must have a target class of D or above.

The application of an objective-based approach by water managers necessitates, firstly, that the desired status of the river has been agreed. And, secondly, that it is possible to define non-linear relationships between flow variables and river health, or preferably threshold flows which trigger some change of state. Jones (2002) suggested that, in Australia, the probability of having a healthy river falls from high to moderate when the hydrological regime is less than two-thirds natural. Whilst this seems a reasonable figure, there is little scientific evidence to support it. Indeed, the complexity of natural systems makes it difficult to define thresholds at which the flow regime will maintain a desired river condition (Acreman, in press), even if such thresholds do indeed exist. Whilst there is a wealth of scientific evidence for basic hydro-ecological relationships (such as the ecological need for floods and droughts) the challenge for scientists is to translate this general knowledge into sitespecific quantified rules, Thus, although environmental flow setting is a practical river management tool, there remains an element of expert or political judgement.

For most river systems of the world, no specific ecological objectives have been set. Furthermore, many regulatory authorities have to balance the needs of water users with environmental concerns. An alternative to the objectivebased approach is for water managers to examine various water allocation options, or scenarios. This is called scenario-based flow setting. For example, there are four

Table 1. Ecological management classes (DWAF, 1999)

\section{Class Description}

A Negligible modification from natural conditions. Negligible risk to sensitive species.

B Slight modification from natural conditions. Slight risk to intolerant biota.

C Moderate modification from natural conditions. Especially intolerant biota may be reduced in number and extent.

D High degree of modification from natural conditions. Intolerant biota unlikely to be present. major pumped groundwater sources in the catchment of the River Wylye in the UK. Setting acceptable abstraction levels has involved consideration of a suite of abstraction scenarios ranging from no abstraction to full abstraction from all sources, with various combinations of different pumping rates in between. For each scenario, the impact on habitat for target fish species and implications for water supply to the public and industry were determined. Relationships between habitat and flow were determined to enable the effects of flow variation to be compared throughout the catchment, taking into account the variations in channel form and size which were evident. These scenarios provided the basis for discussions between stakeholders (including water companies, farmers, local people and fishermen) of acceptable abstraction strategies. Similarly, as part of the Lesotho Highlands Water Project, various scenarios of environmental flow releases from dams were considered. For each scenario, the impacts on the downstream river ecosystems and dependent livelihoods were determined as were the economic implications of water available for sale to South Africa (King et al., 2003). These scenarios permitted the Lesotho government to assess the trade-offs presented by different environmental flow options.

\section{Environmental flow approaches}

The approaches developed in various countries around the world to define environmental flow allocations can be divided into four categories:

- Look-up tables

- Desk top analysis

- Functional analysis

- Hydraulic habitat modelling

Each of these methods may involve more or less input from experts and may address all or just parts of the river system. Consequently, the use of experts and the degree to which methods are holistic (embrace all parts of the system) are considered as characteristics of the various methods and are discussed in separate sections below, as are examples of assessment frameworks within which the methods are used. Other classifications of methods have been undertaken (e.g. Tharme, 2003) which include more sub-divisions. The intention here was to produce a simple classification readily accessible to non-specialists.

\section{LOOK UP TABLES}

Worldwide, the most commonly applied methods to define target river flows have been rules-of-thumb based on simple 
indices given in look-up tables. Traditionally, engineers have used hydrologically-defined indices for water management rules and to set compensation flows below reservoirs and weirs. Examples are percentages of the mean flow or exceedence percentiles from a flow duration curve (i.e. the flow duration curve is a water resources tool that defines the proportion of time that a given flow is equalled or exceeded). This approach has been adopted for environmental flow setting to determine simple operating rules for dams or off-take structures where few or no local ecological data are available. Such indices may be set using various techniques or assumptions, although in practice these distinctions are often blurred on unclear:

(a) purely based on hydrological convenience, perhaps with retrospective ecological justification;

(b) generalised observations on hydro-ecological relationships from an area (catchment or group of catchments); or

(c) more formal (statistical) analysis of hydrological and ecological data from an area.

It is implicit in these indices that they should be based on statistical properties of the natural flow regime, although often this is not specified clearly. A hydrological index is used in France, where the Freshwater Fishing Law (June 1984) required that residual flows in bypassed sections of river must be a minimum of $1 / 40$ of the mean flow for existing schemes and 1/10 of the mean flow for new schemes (Souchon and Keith, 2001). This type of method yields only a fixed or minimum flow and not a whole flow regime.

In regulating abstractions in the UK, an index of natural low flow has been employed to define the environmental flow. $Q_{95}$ (i.e. that flow which is equalled or exceeded for $95 \%$ of the time) is often used. However, in other cases, indices of rarer events (such as mean annual minimum flow) have been used. The figure of $\mathrm{Q}_{95}$ was chosen purely on hydrological grounds. However, the implementation of this approach (e.g. how much $\mathrm{Q}_{95}$ can be reduced) often includes ecological information (Barker and Kirmond, 1998).

Tennant (1976) developed a method using calibration data from hundreds of sites on rivers in the mid-western states of the USA to specify minimum flows to protect a healthy river environment. Misleadingly, it has been called the Montana method, though it is not actually used in Montana. Percentages of the mean flow are specified that provide different quality habitat for fish e.g. $10 \%$ for poor quality (survival), 30\% for moderate habitat (satisfactory) and 60\% for excellent habitat. This approach can be used elsewhere, but the exact indices would need to be re-calculated for each new region. The indices have been adapted for other climatic regions in North America and have been widely used in planning at the river basin level. However, they are not recommended for specific studies and where negotiation is required.

Matthews and Bao (1991) concluded that methods based on proportions of mean flow were not suitable for the flow regimes of rivers in Texas because they often resulted in an unrealistically high flow. Instead, they devised a method that used variable percentages of the monthly median flow, based on fish inventories and known life-history requirements, flow frequency distributions or for special periods and processes (e.g. migration).

The advantage of all look-up approaches is that once the general procedure has been developed, application requires relatively few resources. However, such rapid approaches tend to be calibrated for a particular region and cannot readily be transferred for use elsewhere. Indices based purely on hydrological data are more readily calculated for any new region, as flow data tend to be generally available; however, these have no ecological validity, so uncertainty of results is very high. Indices based on ecological data clearly have more ecological validity but the ecological data for calibration may be costly and time-consuming to collect. Even then they do not necessarily take account of sitespecific conditions. In general, look-up tables are, thus, particularly appropriate for low controversy situations. They also tend to be precautionary.

\section{DESK TOP ANALYSIS}

Methods in this section generally focus on analysis of existing data. However, in some cases they may use data from hydrological models. The methods can be sub-divided into (a) those based purely on hydrological data, and (b) those that employ both hydrological and ecological data.

Hydrological methods in this section examine the whole river flow regime rather than using simple pre-derived statistics. A fundamental principle is to maintain integrity, natural seasonality and variability of flows, including floods and low flows (e.g. drying-out where rivers are ephemeral). For example, floods are important in maintaining the physical structure of the channel by flushing and sorting sediment (Hill and Beschta, 1991).

An example of a desk-top method is the Range of Variability Approach (RVA; Richter et al., 1997) using the indicators of hydrological alteration (IHA; Richter et al. 1996). They developed a hydrological method intended for setting benchmark flows on rivers, where protection of the natural ecosystem is the primary objective. Development of the IHA approach concentrated on identification of the components of a natural flow regime, indexed by magnitude 
(of both high and low flows), timing (indexed by monthly statistics), frequency (number of events), duration (indexed by moving average minima and maxima) and rate of change. The method used gauged or modelled daily flows and a set of 32 indices (Richter et al, 1996). Each index was calculated on an annual basis for each year in the hydrological record and thus concentrates on inter-annual variability in the indices. The question to be addressed is how much deviation from natural ranges of these parameters is too much? Where no ecological information is available to answer this question, the RVA uses a default range of variation based +/ -1 standard deviation from the mean or between the 25 th and 75 th percentiles. This method is intended to define interim standards, which can be monitored and revised. Research to relate the flow statistics to river ecology at the species, community and ecosystem level is ongoing.

Methods that use ecological data tend to be based on statistical relationships between independent variables such as flow to biotic dependent variables. The latter could be simple, such as total abundance or species richness, or more complicated metrics calculated from lists of taxa observed in samples. The advantage of this type of approach is that it directly addresses the two areas of concern (flow and ecology) and takes into account, directly, the nature of the river in question. However, there are some disadvantages.

(a) It is difficult or impossible to derive biotic indices that are sensitive only to flow and not to other factors (e.g. habitat structure, water quality). Hence, biotic indices designed for water-quality monitoring purposes should be used with great caution (Armitage and Petts, 1992).

(b) Lack of both hydrological and biological data is often a limiting factor; sometimes routinely collected data may be gathered for other purposes and not be suitable.

(c) Time series of ecological data may well not be independent, which can violate the assumptions of classical statistical techniques.

A method developed in the UK in this category that involves the use of available ecological data is the Lotic Invertebrate Index for Flow Evaluation (LIFE) (Extence et al., 1999; Dunbar et al., 2004). It is designed to be used with routine macro-invertebrate monitoring data. A metric of perceived sensitivity to water velocity scores all recorded UK taxa on a six- point scale. For a sample, the score for each observed taxon is weighted based on its abundance, and mean score per taxon is calculated. The system works with either species or family level data. For monitoring sites where historical time series of flows are known, the relationship between LIFE score and preceding river flow may be analysed. Moving averages of preceding flow have

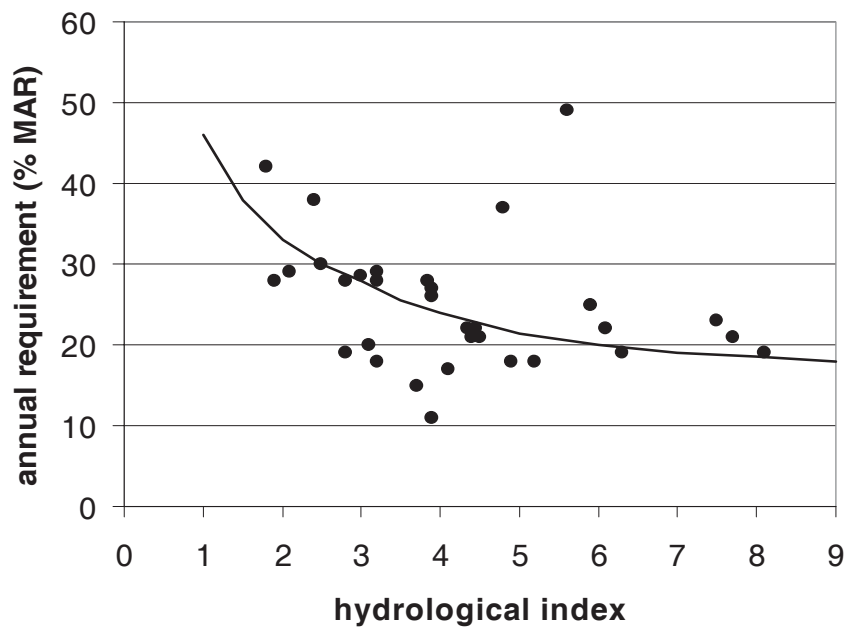

Fig. 1. Relationships developed in South Africa between the hydrological index (CV/BFI) and the percentage of the mean annual runoff (MAR) required to maintain low flows. The curve relates to management categories for rivers in class B (see Table 1). The dots show the results of individual studies using the Building Block Method on B category rivers.

shown good relationships with LIFE scores over a range of sites. The exact manner in which LIFE score variation can be used to manage river flows is still to be determined. Nevertheless, the principle is believed to be sound and LIFE has the major advantage of utilising the data collected by existing bio-monitoring programmes so is compatible with the European Water Framework Directive.

Hughes and Munster (2000) and Hughes and Hannart (2003) developed a desktop method to provide initial estimates of environmental flow needs for rivers in South Africa. The user calculates a hydrological index (i.e. coefficient of variation of flows divided by the proportion of total flow that is base flow; $\mathrm{CV} / \mathrm{BFI}$ ) using river flow data at the site. Then, curves are employed to define the percentage of mean annual runoff (MAR) volume that is required for different components (low flows and floods) of the environmental flow regime.

Figure 1 shows low flow curves for category B rivers (Table 1). The form of these curves was defined by plotting the results of individual detailed environmental flow studies (where ecological data have been collected) on the graph of hydrological index $v \%$ MAR (shown as points for category B rivers).

\section{FUNCTIONAL ANALYSIS}

The third group of methods builds on understanding the functional links between several aspects of the hydrology and ecology of the river system. These methods take a broad 
view and cover many aspects of the river ecosystem and incorporate hydrological analysis, hydraulic rating information and biological data. Implicit in these methods is appreciation that a simple provision of physical habitat for a particular target species is not the only ecological function of river flow. They also make significant use of experts. Perhaps the best known is the Building Block Methodology (BBM) developed in South Africa (Tharme and King, 1998; King et al., 2000); its basic premise is that riverine species are reliant on basic elements (building blocks) of the flow regime, including low flows (that provide a minimum habitat for species and prevent invasive species), medium flows (that sort river sediments, and stimulate fish migration and spawning) and floods (that maintain channel structure and allow movement onto floodplain habitats). A flow regime for ecosystem maintenance can, thus, be constructed by combining these building blocks (Fig. 2). The BBM revolves around a team of experts that normally includes physical scientists, such as a hydrologist, hydrogeologist and geomorphologist, and biological scientists, such as an aquatic entomologist, a botanist and a fish biologist. They follow a series of structured stages, assess available data and model outputs and use their combined professional experience to come to a consensus on the building blocks of the flow regime. The BBM has a detailed manual for implementation (King et al., 2000), is presently used routinely in South Africa to comply with the 1998 Water Act (DWAF, 1999) and has been applied in Australia (Arthington and Long, 1997; Arthington and Lloyd, 1998).

In Australia, several functional analysis methods have been developed (Arthington, 1998), including the Expert Panel Assessment Method (Swales and Harris, 1995), the Scientific Panel Approach (Thoms et al., 1996) and the Benchmarking Methodology (Brizga et al., 2002). As with the BBM, all aspects of the hydrological regime and ecological system are studied by an expert group of physical and biological scientists. They make judgements about the ecological consequences of various quantities and timings of flow in the river, using a mix of available and newly acquired data. On the Murray-Darling Basin (Swales and Harris, 1995) where the river is controlled by dams, the expert panel viewed the river directly at different flows (corresponding to various releases). In other cases, field visits are accompanied by analysis of hydrological data. This integrated approach also involves public meetings with key stakeholders in the catchment.

In the Flow Events Method (FEM) (Stewardson and Gippel, 2003), the authors highlight that the dynamic nature of rivers could invalidate the idea of stable niches dominating inter-species interactions; this has important implications for methods based on hydraulic habitat modelling. However, some desktop methods are so general that they lack any specific detail on ecological response as well as any consideration of river hydraulics and geomorphology. The FEM provides generic methods for analysing the frequency of individual hydraulically-relevant flow indices under alternate flow regimes. It is, thus, strongly suited to scenario analysis but not, so far, to objective setting. The authors suggest an expert panel for the selection of indices in any particular study.

Although conceptually strong, these methods rely on

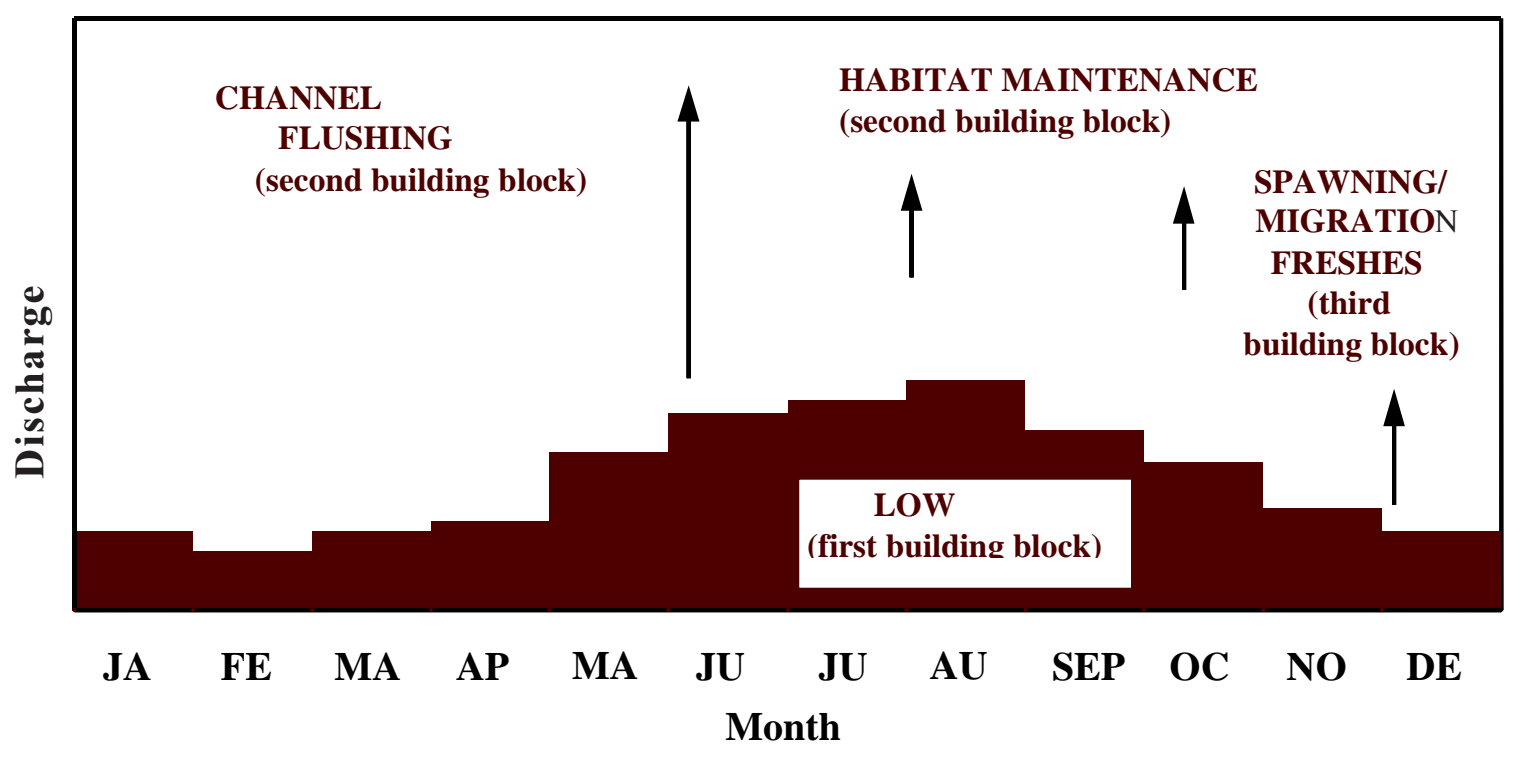

Fig. 2. Example of flow regime built up using building blocks. 
knowledge of the functional relationships between the hydrology and ecology of the river system. Such knowledge may not exist; when it does, it is often in historic reports or in the minds of local ecologists. Turning this knowledge into usable information requires skilled facilitators and often a holistic approach.

\section{HYDRAULIC HABITAT ANALYSIS AND MODELLING}

As discussed above, difficulties exist in relating changes in the flow regime directly to the response of species and communities; hence, approaches have been developed that use habitat for target species as an intermediate step. Within the total environmental niche required by an individual animal or plant living in a river, it is the physical aspects that are affected directly by changes to the flow regime.

The most obvious physical dimension that can be changed by altered flow regimes is the wetted perimeter (area of river bed submerged) of the channel. Hydraulic rating methods provide simple indices of available habitat (e.g. wetted perimeter) in a river at a given river discharge. Graphs of discharge and wetted perimeter provide a basic tool for environmental flow evaluation. As a rule of thumb, shallow, wide rivers tend to show more sensitivity of their wetted perimeter to changes in flow than do narrow, deep rivers. In some cases limited field surveys are undertaken; in others, existing stage-discharge curves from open-river gauging stations are used. This approach has been studied in the USA (Stalnaker and Arnette, 1976; Espegren and Merriman, 1995) and in Australia (Richardson, 1996; Gippel and Stewardson, 1998; Reinfelds et al., in press) although Gippel and Stewardson (1998), amongst others, have highlighted the problems of trying to identify thresholds (critical discharges below which wetted perimeter declines rapidly) that can be used to define minimum environmental flows (Fig. 1). Thus, great care is needed if threshold flows are to be defined, because the methods are sometimes more useful when comparing the implications of alternative scenarios.

More detailed approaches link data on the physical conditions (such as water depths and velocities) in rivers at different flows (either measured or estimated from computer models) with data on the physical conditions required by key animal or plant species (or their individual developmental stages). Once functional relationships between physical habitat and flow have been defined, they are linked to scenarios of river flow.

The first step in formulating this approach for rivers was published by Waters (1976); he invented the concept of weighted usable area defined by physical variable such as depth and velocity. This led, quickly, to the more formal description of a computer model called PHABSIM (Physical
Habitat Simulation) by the US Fish and Wildlife Service (Bovee, 1982). As implemented in a number of software packages, the traditional PHABSIM approach uses onedimensional hydraulic models, adapted to handle low flow conditions and to model cross-sectional velocities. These are coupled with univariate representations of habitat suitability or preference to define how usable habitat (termed weighted usable area) changes with flow. The extent of the change will be specific to the species under consideration and it differs, frequently for different developmental stages. The physical habitat modelling approach has now been adapted in many countries (Parasiewicz and Dunbar, 2001), including France (Ginot, 1995), Norway (Killingtviet and Harby, 1994) and New Zealand (Jowett, 1989), while other countries, independently, have developed similar approaches e.g. Germany (Jorde, 1996).

Physical habitat modelling has been used to estimate the effects (in terms of usable physical habitat) for historic or future anticipated changes in flow caused by abstraction or dam construction. The method has evolved from a steadystate consideration of flows giving certain levels of habitat, to time-series analysis tools which consider the entire flow regime (actual or modelled) in the river. In turn, these tools have developed from simple flow and habitat duration curves to more in-depth analysis of habitat reductions under various scenarios (Dunbar et al., 2004).

Several aspects of these approaches, involving both hydraulic and habitat modelling, began to be criticised in the 1980s. In particular, the linking of environmental flows solely to habitat preferences in PHABSIM and similar models is simplified and empirical. Since then, numerous specific modelling applications have demonstrated some improvement. However, these have yet to give rise to a single package as the logical replacement to PHABSIM. Greater hydraulic process representation may be achieved using $2 \mathrm{D}$ and $3 \mathrm{D}$ computational fluid dynamics models (Alfredsen et al., 1997; Booker, 2003). New approaches to quantify hydraulic habitat have been published (Peters et al., 1995; Nestler and Sutton, 2000). New habitat models have included additional variables and have been expanded to the community level (Bain et al., 1988; Bain, 1995; Lamoroux et al., 1998; Parasiewicz, 2001). More physicallybased models of fish habitat use (e.g. Guensch et al., 2001; Booker et al., 2004) also have potential to improve environmental flow methods (Hardy, 1998).

All of these improvements currently come at a cost of increased complexity, although, in future, it is hoped that more general rules are derived to develop improved lookup methods (Lamouroux and Capra, 2002) and to define the impacts of river flow regulation on populations rather than habitats. 
One advantage of this habitat modelling approach is that manuals define step by step procedures, which allow replication of results by different individuals or teams of researchers. However, it can also lead to poor applications by practitioners with inadequate training. Best results are obtained where teams, including hydraulic engineers, hydrologists and ecologists, work together using habitat modelling as a structure.

\section{Holistic approaches}

Many early applications of environmental flow setting were focused on single species or single issues. For example, much of the demand for environmental flows in North America and northern Europe was from sport fishermen concerned about the decline in numbers of trout and salmon because of abstractions and dam operations. Environmental flows were then set to maintain critical levels of habitat (particularly water velocity and depth) for these target species. Part of the justification was the belief that these species are very sensitive to flow so that if the flow is appropriate for them, it will be for other parts of the ecosystem. However, in many situations, this justification is not necessarily true; there is a general view that environmental flow assessments should consider all aspects of the river ecosystem and thus be 'holistic' in their application. In some ways, even purely hydrological methods (such as RVA/IHA) can be said to be holistic. The concept that if the flow regime is natural, all elements of the ecosystem will be supported is implicitly if not explicitly holistic.

More and more methods now take a holistic approach that includes assessment of the whole ecosystem, such as associated wetlands, groundwater and estuaries, as well as all species that are sensitive to flow (e.g. vertebrates, invertebrates, higher and lower plants and algae) and all aspects of the hydrological regime; floods, droughts and water quality. A fundamental principle is to maintain the natural variability of flows. The functional analysis approaches described above can be closely linked to the holistic concept (Arthington, 1998; King et al., 2003). However, habitat modelling studies can also include assessment of multiple developmental stages and multiple species, and can consider required flows for sediment transport and channel maintenance. Thus, holistic is a characteristic increasingly found in all environmental flow methods.

To manage the complex assessment of flow impacts at the ecosystem level, holistic approaches necessarily place greater emphasis on expert opinion than on modelling; they may involve participation of stakeholders, so that the procedure is holistic in terms of interested parties as well as of scientific issues. Where methods are holistic, they clearly have the advantage of covering the whole hydrologicalecological-stakeholder system. If such methods are to be based on actual data, the collection of the data could well be expensive and time consuming, hence the current reliance on experts.

\section{The role of experts in environmental flow assessment}

Environmental flow assessment is a specialised subject and necessarily involves experts. There are rarely sufficient data available on all these topics to produce an integrated objective method that can be used by a non-expert. Thus, all methods depend on some expert opinion. In the early days and in the development of look-up tables, single experts often gave their opinion, particularly where data were scarce. For example, an expert might classify a river into a specific category within a look-up table to set the environmental flow. When relying on the opinion of single experts, findings are inevitably dependent on the particular experts used and on their experience with environmental flows. Hence, use of expert opinion in this way can be subjective, inconsistent and crucially, non-transparent.

An alternative is to form a multi-disciplinary team of experts from different fields, who can form a consensus that is more robust and acceptable to all the interested parties. The team approach is consistent with the recognition that environmental flow assessment is a multi-disciplinary subject, requiring input from a wide range of specialist areas including hydrology, hydraulics, geomorphology, water quality and ecology.

The Australian functional analysis methods (e.g. Expert Panel Assessment Method) and the South African Building Block Methodology all make extensive use of a team of experts. The team usually includes a hydrologist, hydrogeologist, aquatic entomologist and botanist, geomorphologist, and a fish biologist. They make judgements in a structured manner about the ecological consequences of various quantities and timings of flow in the river. Where the river is controlled by upstream impoundments, the expert panel may view the river directly at different flows (corresponding to various releases); otherwise, field visits will be accompanied by analysis of hydrological data. Habitat modelling studies can equally make use of expert opinion, for example to derive habitat suitability indices.

The advantage of this approach is its flexibility and consensus-building amongst experts who reach the best solution based on the data and model results available. The 
disadvantage is that it is not necessarily replicable; another group of experts might come to different conclusions. In addition, not only do the biological experts need to have a good understanding of their field and the functioning of the river under examination, they must also have a basic understanding of hydrology. Such panels need experienced facilitators and, ideally, the expert members must be trained in formulating their expert knowledge so that it contributes to the goals of the study. There is also a mis-match in terminology and scales between traditional disciplines (e.g. different interpretations of the word 'flow'), although the emergence of new interdisciplinary subjects such as hydroecology (Acreman, 2001) and eco-geomorphology (Thoms and Parsons, 2002) may overcome this.

To some extent, the development of habitat modelling was driven by the desire to produce results which are more replicable, i.e. free from subjective views. Nevertheless, this form of modelling still requires expert judgement as various decisions must be made, such as in calibrating hydraulic models and selecting appropriate habitat suitability indices. However, the detailed step-by-step approach in such models provides a very structured procedure with key decision points that can be quality assured.

In recent years, increasingly, stakeholders have been included in the analysis which may include experts on river functioning (e.g. conservation organisations or water companies) and non-experts (e.g. from industry or the general public). If stakeholders are to be involved in the decision-making process, it is vital that the methods employed are acceptable to them. Although for adequate understanding environmental flow methods some stakeholders will be limited by their background knowledge, often their knowledge of the river can be invaluable. Some stakeholders may have had training in related subjects such as water supply, agriculture and industrial processes and can play an influential role in flow assessment.

\section{Assessment frameworks}

The approaches described above are normally incorporated into a wider assessment framework that identifies the problem, uses the best technical method and presents results to decision-makers. Three frameworks are considered.

\section{INSTREAM FLOW INCREMENTAL METHODOLOGY} (IFIM)

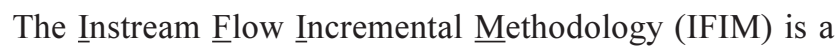
framework for addressing the impacts on river ecosystems of changing a river flow regime (Bovee, 1982; Bovee et al., 1998). The US Fish and Wildlife Service (the Instream Flow
Group of which is now part of the US Geological Survey Biological Resources Division) developed IFIM. In some states of the USA, the use of IFIM has become a legal requirement for assessing the impacts of dams or abstractions. It has five main steps.

(1) The problems are identified and broad issues and objectives are related to legal entitlement identification

(2) The technical part of the project is planned in terms of characterising the broad-scale catchment processes, species present and their life history strategies, identifying likely limiting factors, collecting baseline hydrological, physical and biological data.

(3) Models of the river are constructed and calibrated. IFIM distinguishes between microhabitat, commonly modelled using an approach such as PHABSIM, and macro-habitat, which includes water chemistry/quality and physico-chemical elements such as water temperature. There is a structure for specifying channel and floodplain maintenance flows but there is little guidance on specific methods. Hydrological models of alternative scenarios, including a baseline of either naturalised or historical conditions, drive the habitat models. The models are integrated, using habitat as a common currency.

(4) Alternative scenarios of dam releases or abstraction restrictions are formulated and tested using the models to determine the impact of different levels of flow alteration on individual species, communities or whole ecosystems.

(5) The technical outputs are used in negotiations between different parties to resolve the issues set out in step one.

Disadvantages of IFIM arise partly from its comprehensive nature; a full study takes a considerable time and because of the wide range of issues included, provides numerous avenues for criticism. Furthermore, it is important to understand the limitations of the models used, what they include, leave out or simplify, and any further issues arising from the linkages of models. Quantification of uncertainty is an element that is frequently overlooked. Many 'IFIM' studies have been criticised, often because the framework was not applied in its entirety. Commonly, emphasis has been placed on the stage 3 modelling, at the expense of the other stages, which are critical. Paradoxically, IFIM studies have also been criticised for being too institutionalised and inflexible. Finally, the approach is fundamentally an incremental procedure, suited to comparison of scenarios. The fact that it does not give a single answer has been viewed as both a disadvantage and an advantage.

Advantages of IFIM include its comprehensive framework 
for considering both policy and technical issues and its problem-orientated structure. Its implicit quantitative nature is generally considered an advantage, integrating micro- and macro-habitat. Furthermore, its scenario-based approach is favoured for negotiations between water users but it may be less suitable in setting flow regimes to comply with ecological objectives.

\section{DOWNSTREAM RESPONSE TO IMPOSED FLOW} TRANSFORMATION

The Downstream Response to Imposed Flow Transformation (DRIFT) framework (King et al., 2003) was developed in South Africa with its first major application being in Lesotho (Lesotho Highlands Development Authority, 2002). Like the Building Block Methodology and similar methods, it aims to address all aspects of the river ecosystem. It is also scenario-based, providing decisionmakers with options (scenarios) of future flow regimes for the river of concern, together with the consequences for the condition of the river. Probably its most important and innovative feature is a strong socio-economic module, which describes the predicted impacts of each scenario on subsistence users of the resources of a river.

DRIFT has four modules:

(1) Biophysical. Within the constraints of the project, scientific studies are made in all aspects of the river ecosystem: hydrology, hydraulics, geomorphology, water quality, riparian trees and aquatic and fringing plants, aquatic invertebrates, fish, semi-aquatic mammals, herpetofauna and microbiota. All studies are linked to flow, so as to predict how any part of the ecosystem will change in response to specified changes in flow.

(2) Socio-economic. Social studies are made of all river resources used by common-property users for subsistence, and the river-related health profiles of these people and their livestock. The resources used are costed. All studies are linked to flow, to predict how the people will be affected by specified river changes (last module).

(3) Scenario-building. For any future flow regime the client would like to consider, the predicted change in condition of the river ecosystem is described using the database created in modules 1 and 2 . The predicted impact of each scenario on the common-property subsistence users is also described, together with its uncertainty. DRIFT provides a routine for optimising the flow regime that gives maximum benefits for a given volume of water available.

(4) Economics. The compensation costs of each scenario for common-property users are calculated.

If there are no common-property subsistence users, modules 2 and 4 can be omitted. Although DRIFT is usually used to build scenarios, its database can equally be used to set flows for achieving specific objectives. The 'DRIFT Solver' can optimise ecological condition through combinations of dam releases of different timings, magnitudes and durations, given a set annual environmental allocation of water.

Two activities outside DRIFT provide additional information to the decision-maker:

(a) a macro-economic assessment of each scenario, to describe its wider regional implications in terms of industrial and agricultural development, cost of water to urban areas and so on; and

(b) a public participation process, in which the wider body of stakeholders can voice its level of acceptability of each scenario.

DRIFT has also been applied to the Breede and Palmiet Rivers in South Africa and, in an abbreviated rapid form, in Zimbabwe. Implementation of the chosen scenarios is already underway in the Palmiet system and in Lesotho. Because of its multidisciplinary nature, a comprehensive DRIFT application could cost a million US\$ or more for a large river system, and less for a smaller system. It is often an issue of trade-offs, however, and the greater the investment in investigative studies, the higher is the confidence in the scenarios produced. To put this into perspective, most environmental flow assessments are done as part of the project planning for a new dam: even a comprehensive DRIFT study will probably cost less than $1 \%$ of the total cost of many dams.

\section{CATCHMENT ABSTRACTION MANAGEMENT STRATEGIES (CAMS)}

The Environment Agency of England and Wales is responsible for ensuring that the needs of water users are met whilst safeguarding the environment. To implement this responsibility in a consistent manner, the Agency has

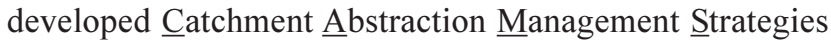
(CAMS) (Environment Agency, 2002).

The CAMS process includes participation of interested parties through catchment stakeholder groups and a Resource Assessment and Management (RAM) framework. The Stakeholder Group normally includes abstractors (water supply companies, industry and farmers) and other water users (navigation, fishing) and local wildlife groups. 
Stakeholder involvement is at an early stage and is consultative rather than truly participatory. RAM is intended as a default methodology in the absence of other more sophisticated techniques.

The environmental flow needs of any river are related purely to the sensitivity of the ecosystem to reduced flow. Rivers are not classified according to use or broad objectives, as in Table 1. This is broadly in line with the Water Framework Directive requirements to achieve 'Good Status' (GS) in all surface waters. The first step in calculating the sensitivity of the river to reduced flow is to determine the 'environmental weighting'. Four elements of the ecosystem are assessed: 1. Physical character; 2. Fisheries; 3. Macrophytes; 4. Macro-invertebrates. Each element is given a RAM score from 1-5 (1 being least sensitive to reductions in flow, 5 being most sensitive). In terms of physical characterisation, rivers with steep gradients and/or wide shallow cross sections score 5, since small reductions in flow result in a relatively large reduction in wetted perimeter. Lowland river reaches that are narrow and deep, are less sensitive to flow reduction and score 1. Physical character is determined by comparing the river with photographs of typical river reaches in each class. Scoring for fisheries is generally determined by the expert opinion of Environment Agency fisheries staff to classify the river according to the description of each of the RAM score classes. Scoring for macro-invertebrates and macrophytes uses flow-sensitive metrics such as the LIFE score described above.

Once a score for each of the four elements has been defined, the scores are combined to categorise the river into one of five Environmental Weighting Bands, where Band A (5) is the most sensitive (average score of 5) and Band E is the least sensitive (average score of 1). In a separate part of the RAM framework, a flow duration curve (for natural flows) is produced. The RAM framework then specifies allowable abstractions at different points (flow percentiles) of the curve for each weighting band. Table 2 shows the percentage of natural $Q_{95}$ flow that can be abstracted,

Table 2. Percentages of natural $\mathrm{Q}_{95}$ flow that can be abstracted for different environmental weighting bands.

\begin{tabular}{ll}
$\begin{array}{c}\text { Environmental weighting } \\
\text { band }\end{array}$ & $\%$ of $Q_{95}$ that can be abstracted \\
\hline A & $0-5 \%$ \\
B & $5-10 \%$ \\
C & $10-15 \%$ \\
D & $15-25 \%$ \\
E & $25-30 \%$ \\
Others & Special treatment \\
\hline
\end{tabular}

although these are not well supported by hydro-ecological studies and are intended only as a default method. More detailed methods, such as habitat modelling, are recommended where environmental flows need to be defined in more detail. The RAM framework focuses on producing an ecologically acceptable flow duration curve. The flow duration curve retains many characteristics of the flow regime, such as the basic magnitude of droughts, low flows and floods. However, it does not retain other characteristics, including temporal sequencing, duration or timing of flows, which may be important for the river ecosystem (Poff et al., 1997). An ecologically acceptable flow duration curve is most appropriate where the river ecosystem is controlled by seasonal characteristics of dry season/wet season or winter/summer flows. Further details of the RAM framework are given in Dunbar et al. (2004).

\section{Choice of method}

There is no simple choice for which method is the best or most appropriate. Some of the advantages and disadvantages of different approaches are summarised in Table 3. The main driving force for choice of method is the type of issue to be addressed. These fall into four categories: scoping, basin planning, impact assessment and river restoration.

(a) Scoping includes national assessments to identify areas in which water allocation is potentially contentious, and national auditing, such as to determine general level of river health. In these cases, where many river basins need to be assessed, a rapid method such as a look-up table would be most appropriate.

(b) Basin scale planning involves the assessment of environmental flows through an entire river basin. In this case, assessment may begin with use of look-up tables to home-in on critical sites. Then a desk-top approach would be most appropriate. Further investigation probably comes under the heading of 'impact assessment'. The development of Catchment Abstraction Management Plans in the UK (Environment Agency, 2002) employs simple look-up tables as the default method to determine a river basin's water availability status (Dunbar et al., 2004).

(c) Impact assessment. In many cases, environmental flow assessment involves impact assessment and mitigation of specific flow modifications such as dams or major abstractions. Where there is a single impacted site, particularly where water allocation is highly contentious and might lead to a public inquiry, a detailed modelling 
Mike Acreman and Michael I Dunbar

Table 3. Some advantages and disadvantages of different methods and characteristics of setting environmental flows.

\begin{tabular}{|c|c|c|c|}
\hline Method type & Sub-type & Advantages & Disadvantages \\
\hline \multirow[t]{2}{*}{ Look-up table } & Hydrological & Cheap, rapid to use once calculated & $\begin{array}{l}\text { Not site-specific. Hydrological indices not valid } \\
\text { ecologically }\end{array}$ \\
\hline & Ecological & & $\begin{array}{l}\text { Ecological indices need region-specificdata to be } \\
\text { calculated }\end{array}$ \\
\hline \multirow[t]{3}{*}{ Desk top } & Hydrological & Site specific & Long time series required \\
\hline & Hydraulic & Limited new data collection & No explicit use ofecological data \\
\hline & Ecological & & Ecological data time consuming to collect \\
\hline Functional analysis & & $\begin{array}{l}\text { Flexible, robust, more focused on } \\
\text { whole ecosystem }\end{array}$ & $\begin{array}{l}\text { Expensive to collect all relevant data and to employ } \\
\text { wide range of experts. Consensus of experts may } \\
\text { not be achieved. }\end{array}$ \\
\hline Habitat modelling & & Replicable, predictive & Expensive to collect hydraulic and ecological data \\
\hline
\end{tabular}

method is normally needed and a developer or regulatory authority would be more willing to fund the high costs. Where the impact is spread over several sites within a river basin, it may appropriate to make initial assessments of the impact around the basin using a desktop method before more specific functional analysis or hydraulic habitat modelling is undertaken as part of an holistic approach. In such cases, look-up approaches are not appropriate. The use of habitat models to assess the impact of water resources development is mandatory in some states of the USA and has been widely used in other countries in Europe and in New Zealand.

(d) River restoration. In the strictest sense, restoration is the re-establishment of the structure and function of an ecosystem (National Research Council, 1992) to its natural condition. In practice, full restoration is seldom possible, due to major abstractions, dams or floodplain developments and lack of knowledge of the true natural condition. As a result, the term 'rehabilitation' is often used to describe re-instating ecosystem structure and function to some agreed level. In the context of environmental flows, this could involve reduced abstraction, releases from reservoirs and structural measures, such as re-instatement of meanders. The holistic approaches allow assessment of the benefits of any restoration activities, in terms of enhanced functioning of all parts of the river ecosystem. Physical habitat modelling has also been used in several countries to assess the effectiveness of morphological restoration schemes (Schuler and Nehring, 1994; Elliott et al., 1999; Vehanen et al., 2000).

A summary of this selection approach is given in Table 4 . The level of expert input required again depends on how contentious decisions will be. In general, involving a group of experts will produce more credible results than using single experts. In addition, the highly structured use of

Table 4. Choice of environmental flow assessment methods

Look up Desk top_ Functional analysis Habitat modelling

\begin{tabular}{ll}
$\begin{array}{ll}\text { Scoping study or national audit } \\
\text { Basin-scale planning }\end{array}$ & \\
Impact assessment & $\begin{array}{l}\text { Multi-site } \\
\text { Single -site }\end{array}$ \\
River restoration & $\begin{array}{l}\text { Multi-site } \\
\text { Single -site }\end{array}$ \\
\hline
\end{tabular}

$\mathrm{X}$

$\longleftrightarrow$ Single -site 
experts in the Building Block and other holistic approaches produces far more robust results than ad hoc meetings.

In most countries where environmental flows have been set, a range of methods has been used depending on the data available and types of issues. Furthermore, a tiered approach is adopted in many countries, where environmental flow assessment begins with lookup and desk top methods at scoping level and then progresses to functional analysis methods for feasibility studies supported by hydraulic habitat models where appropriate.

\section{Implementation}

\section{IMPLEMENTING RIVER FLOW MANAGEMENT THROUGH CONTROL POINTS}

Defining the environmental river flow is only part of the procedure for achieving river protection. Implementing the desired state is equally important and depends on the nature of flow management. Active flow management refers to generating the desired flow, such as a release from a reservoir. In contrast, restrictive flow management refers to regulation of abstractions or diversions.

Both active and restrictive management require target flows to be specified and measured. Some of the methods for specifying flows have been described above. Measurement of flows must be undertaken at gauging stations which then become 'control points'.

While the term 'minimum flow' has often been used in this context, it is unsatisfactory unless it is related to a flow maintained for human needs, such as navigation or downstream uses. In general, river ecosystems are adapted to a whole flow regime and as stated previously, any alteration of the regime will lead to ecological change (Petts, et al., 1995). Too much water at the wrong time can be as damaging as too little water.

\section{RESTRICTIVE MANAGEMENT}

In restrictive management, the concept of a 'hands-off' flow (Barker and Kirmond, 1998) or 'cease to pump' flow (Reinfelds et al., in press) is most commonly used. Abstraction is permitted provided that the flow is above a certain critical value, but it must reduce, or cease, when the flow falls below this value. The flow may continue to fall, but this will be at a natural rate governed by meteorological and geological conditions, rather than artificial influences.

\section{ACTIVE MANAGEMENT}

This can be achieved by making releases from a reservoir, or from direct groundwater pumping into a river. In the context of dams, the term 'compensation flow' has been used to refer to low flows released to fulfil downstream requirements. The terms 'maintained flow' and 'stream support' are used in the context of groundwater.

Active flow management may involve identifying and monitoring an analogue broadly-natural catchment. Flows on the target river are then managed to match, with appropriate scaling, the flows on the analogue river. This is sometimes known as the 'Translucent Dam' approach (Blanch, 1999). However, matching the natural flows precisely may require constant changing of the releases, which may be impractical, so the flow regime on the target river may be more simple. In many cases, existing dams were not designed with appropriate structures to allow high flows to be released (Acreman, 2003), so it may be impossible to generate desired floods in the flow regime. If the reference location of the desired flow regime is some distance downstream of the dam or abstraction point, relationships between flow at the two sites will need to be determined. This will include the travel time and attenuation of the hydrograph (i.e. changes in flow). This may also need to consider any inflows between the two, especially major tributaries, which may involve rainfall-runoff forecasting (Acreman, 1996). Particular challenges exist for groundwater abstractions due to the time lag between groundwater abstraction and its impact on river flows (Acreman et al., 2000).

\section{COPING WITH NATURAL VARIABILITY}

Environmental flow regimes are usually set based on longterm data, so flow indices consequently relate primarily to average conditions. Management of artificial influences on river flows against the background of climate variability offers major challenges. Management rules may be complex, with abstraction or reservoir release rates varying with climatic conditions. A further complication is that in some situations, most water is required when least is available. Under severe drought conditions, some countries allow Drought Orders that permit abstraction to be increased above the normal licensed rate. In addition, in Europe environmental requirements can also be relaxed if there are overriding economic, social health or safety considerations (European Commission, 1992).

\section{MONITORING OF EFFECTS}

A final but crucial aspect of implementing river flow requirements is evaluation of success. If the intention to ensure given flow conditions is primarily to conserve the river ecosystem, the health of the river must be monitored 
to establish whether the flows were effective. In the case of objective based flow setting, the appropriateness of the flow objective can be evaluated. Even in the case of scenariobased flow setting, it is envisaged that, although the rationale is to balance instream needs and non-river use needs, the instream needs are sufficient to maintain basic ecosystem functioning. Where flows are found to be ineffective, reassessment is required, the flow regime must be altered and the river system monitored further, in an adaptive management process (Holling, 1978). Because of the lack of predictive ecological models, adaptive management has been advocated as a paradigm for many ecological restoration situations and is increasingly being suggested in the context of rivers (Clark, 2002).

Long term monitoring will be required to ensure river health that respond slowly to changing flow regime. This is particularly important where a river has suffered from lower than target flows in the past and implementation represents restoration. Extreme natural events, including floods and droughts, may disrupt recovery.

\section{Conclusions}

There is a growing demand worldwide to conserve or restore the ecological health and functioning of rivers and their associated wetlands for the benefit of people and biodiversity. It is widely recognised that any artificial alteration to a river flow regime will change the river ecosystem. River managers need to be able to define the river environmental flow regime that will support the desired ecosystem and to quantify the ecological impacts of changes to the flow regime caused by artificial influences, such as abstractions and dam operations. There is no simple figure that can be given for the environmental flow requirements of rivers ecosystems. They are complex systems, knowledge is limited and much depends on social choice that determines the desired character of the river ecosystem under study. The challenge for river scientists is to support decisionmakers in defining the flow regime that best meets the objectives set, or makes the trade-off that society finds most acceptable. A range of methods now exists to achieve this together with broader decision making frameworks. No single method is universally the best; each method has its advantages and disadvantages depending on the climatic regimes and different scales, and each works at various levels of detail. All the methods would benefit from further development but research into generic issues, such as the best way to employ expert knowledge, may yield the greatest benefits.

Hydro-ecology as a science is still young and much is still to be learnt, but the methods and frameworks available even now demonstrate the desire to help improve and protect river ecosystems using the best knowledge with the involvement of local communities and other stakeholders.

\section{Acknowledgements}

The background research for this paper was funded by the Environment Agency for England and Wales project 'Overseas Approaches to Setting River Flow Objectives' (Reference W6-161) and the UK Natural Environment Research Council. The framework was developed further for the IUCN Water and Nature Initiative in collaboration with Jackie King, funded by the UK Department for International Development. The authors are grateful for constructive criticism from Brian Richter (Nature Conservancy, USA) and from anonymous referees.

\section{References}

Acreman, M.C., 1996 Environmental effects of hydro-electric power generation in Africa and the potential for artificial floods. Water Environ. Manage., 10, 429-434.

Acreman, M. C. (ed), 2001. Hydro-ecology: linking hydrology and aquatic ecology. IAHS Publ. no. 266.

Acreman, M.C., 2003. Case studies of managed flood releases. Environmental Flow Assessment Part III. World Bank Water Resources and Environmental Management Best Practice Brief 8, World Bank, Washington DC., USA.

Acreman, M.C., in press. Linking science and decision-making: features and experience from environmental river flow setting. Environ. Model. Software.

Acreman, M.C. and Elliott, C.R.N., 1996. Evaluation of the river Wey restoration project using the Physical HABitat SIMuation (PHABSIM) model. Proc. MAFF Conf. River and Coastal Engineers, Keele, UK. 3-5 July 1996.

Acreman, M.C. and King, J., 2003. Defining water requirements. In: Flow: the essentials of environmental flows, M. Dyson, G. Bergkamp and J. Scanlon (Eds.), IUCN, Gland Switzerland and Cambridge, UK

Acreman, M.C., Adams, B., Birchell, P. and Connorton, B., 2000. Does groundwater abstraction cause degradation of rivers and wetlands? J. Chart. Inst. Water Environ. Manage., 14, 200206.

Alfredsen, K., Marchand, W., Bakken, T.H. and Harby, A. 1997. Application and comparison of computer models quantifying impacts of river regulation on fish habitat. - In: Proc 3rd Int. Conf. Hydropower' 97 - Trondheim / Norway 30 June - 2 July 1997, E.Broch, D.K.Lysne, N. Flatabo and E.Helland-Hansen (Eds.), Balkema, Rotterdam, The Netherlands.

Armitage, P. and Petts, G.E., 1992. Biotic score and prediction to assess the effects of water abstraction on river macroinvertebrates for conservation purposes. Aquat. Conserv., 2, 1-17

Arthington, A.H., 1998. Comparative Evaluation of Environmental Flow Assessment Techniques: review of holistic methodologies. Occasional Paper no. 26/98. Land and Water Resources Development Corporation, Canberra, Australia.. 
Arthington, A.H. and Lloyd, R., (Eds.), 1998. Logan River Trial of the Building Block Methods for assessing environmental flow requirement: Workshop report. Centre for Catchment and Instream Research and Department of Natural Resources, Queensland, Australia.

Arthington, A.H. and Long, G.C., (Eds.), 1997 Logan River Trial of the Building Block Methods for assessing environmental flow requirement:background papers. Centre for Catchment and Instream Research and Department of Natural Resources, Queensland, Australia.

Barker, I. and Kirmond, A., 1998. Managing surface water abstraction. In: Hydrology in a changing environment, vol.1, H.Wheater and C.Kirby (Eds.), British Hydrological Society, London, UK. 249-258.

Bain, M.B., 1995. Habitat at the local scale: multivariate patterns for stream fishes. Bull. Fr. Peche Pisic. 337/338/339, 165-177.

Bain, M.B., Finn, J.T. and Booke, H.E., 1988. Streamflow regulation and fish community structure. Ecology, 69, 382-392.

Blanch, S., 1999. Environmental flows: present and future. Available on http://www.ncensw.org.au/member/wetlands/news/ media/19991118 EFpaper.html

Booker, D.J., 2003. Hydraulic modelling of fish habitat in urban rivers during high flows. Hydrol. Process., 17, 577-599.

Booker, D.J., Dunbar, M.J. and Ibbotson, A.T. (in press). Predicting juvenile salmonid drift-feeding habitat quality using a threedimensional hydraulic-bioenergetic model. Ecol. Model.

Bovee, K.D., 1982. A guide to stream habitat analysis using the IFIM. - US Fish and Wildlife Service Report FWS/OBS-82/ 26. Fort Collins, USA.

Bovee, K.D., Lamb, B.L. , Bartholow, J. M., Stalnaker, C. B., Taylor, J. G., and Henriksen, J., 1998. Stream Habitat Analysis Using the Instream Flow Incremental Methodology: Biological Resources Discipline Information and Technology Report USGS/BRD-1998-0004, viii +131pp.

Brizga, S.O., Arthington, A.H., Choy, S.C., Kennard, M.J., Mackay, S.J., Pusey, B.J. and Werren, G.L., 2000. Benchmarking a top-down methodology for assessing environmental flows in Australian rivers. Proc. Int. Conf. Environmental Flows for River Systems, Cape Town, South Africa. 2002.

Clark, M.J., 2002. Dealing with Uncertainty: Adaptive Approaches to Sustainable River Management. Aquat. Conserv.: Mar. Freshwater Ecosyst., 12, 347-364

Costanza, R. and 15 co-authors., 1997. The value of the world's ecosystem services and natural capital. Nature, 387, 253-260.

Department of Water Affairs and Forestry, 1999. Resource directed measures for protection of water resources. Department of Water Affairs and Forestry, Pretoria, South Africa.

Dunbar, M.J. and Acreman, M.C., 2001. Applied hydro-ecological science for the 21st Century. IAHS Publ. No. 266, 1-18.

Dunbar, M.J., Acreman, M.C. and Kirk, S., 2004. Environmental flow setting in England and Wales - current practice: future challenges. J. Water Environ. Manage., 18, 5-10.

Dunbar, M.J., Acreman, M.C., Gustard, A. and Elliott, C.R.N., 1998. Overseas Approaches to Setting River Flow Objectives. Phase I Report to the Environment Agency. Environment Agency R\&D Technical Report W6-161. 82pp.

Dyson, M., Bergkamp, G. and Scanlon, J. (Eds.), 2003. Flow: essentials of environmental flows. IUCN, Gland, Switzerland and Cambridge, UK.

Elliott, C.R.N., Dunbar, M.J., and Acreman, M.C. 1999. A Habitat Assessment Approach to the Management of Groundwater Dominated Rivers. Hydrolog. Process., 13, 459-475.

Environment Agency, 2002. Managing Water Abstraction, the Catchment Abstraction Management Process. Available from http://www.environment-agency.gov.uk/commondata/105385/ mwa_english.pdf
Espegren, G.D. and Merriman, D.C., 1995. Development of Instream Flow Recommendations in Colorado using R2-Cross. - Colorado Water Conservation Board.

European Commission and Parliament, 1992. Directive 92/43/EEC of 21 May 1992 on the conservation of natural habitats and of wild fauna and flora. European Parliament and Council, Luxembourg.

European Commission and Parliament, 2000. Directive 2000/60 EC of 20 December 2000 establishing a framework for community action in the field of water policy. European Parliament and Council, Luxembourg.

Extence, C., Balbi, D.M. and Chadd, R.P., 1999. River flow indexing using British benthic macro-invertebrates: a framework for setting hydro-ecological objectives. Regul. River., 15, 543574.

Ginot, V., 1995. EVHA, Un logiciel d'evaluation de l'habitat du poisson sous Windows. Bull. Fr. Peche Pisic. 337/338/339: 303308.

Gippel, C. and Stewardson, M., 1998. Use of wetted perimeter in defining minimum environmental flows. Regul. River., 14, 53-67

Guensch G.R., Hardy T.B. and Addley R.C., 2001. Examining feeding strategies and position choice of drift-feeding salmonids using an individual-based, mechanistic foraging model. Can. J. Fisheries Aquat. Sci., 58, 446-457

Gustard, A., Cole, G., Marshall, D. and Bayliss, A., 1987. A study of compensation flows in the UK. Institute of Hydrology Report 99, Wallingford, UK.

Hardy T.B., 1998. The future of habitat modelling and instream flow assessment techniques. Regul.River., 14, 405-420.

Hill, M.T. and Beschta, R.L., 1991. Ecological and geomorphological concepts for instream and out-of-channel flow requirements. Rivers 2, 198-210.

Holling, C.S. 1978. Adaptive environmental assessment and management. Wiley, NY, USA. 377pp.

Hughes, D.A. and Munster, F., 2000. Hydrological information and techniques to support the determination of the water quantity component of the ecological reserve for rivers. Report to the Water Research Commission, Pretoria, RSA. Institute for Water Research, Rhodes University, WRC Report No 867/3/ 2000.

Hughes, D.A. and Hannart, P., 2003. A desktop model used to provide an initial estimate of the ecological instream flow requirements of rivers in South Africa. J. Hydrol., 270, 167-181.

Jones, G., 2002. Setting environmental flows to sustain a healthy working river. Watershed, February 2002, Cooperative Research Centre for Freshwater Ecology, Canberra (http:// freshwater.canberra.edu.au).

Jorde, K., 1996. Ecological evaluation of Instream Flow Regulations based on temporal and spatial variability of bottom shear stress and hydraulic habitat quality. In: Ecohydraulics 2000, $2^{\text {nd }}$ International Symposium on Habitat Hydraulics, M. Leclerc et al. (Eds.), Quebec City, Canada.

Jowett, I.G., 1989. River hydraulic and habitat simulation, RHYHABSIM computer manual. New Zealand fisheries miscellaneous Report 49. Ministry of Agriculture and Fisheries, Christchurch. New Zealand. 39pp.

Junk, W.J., Bayley, P.B. and Sparks R.E., 1989. The flood pulse concept in river-floodplain systems. Can. J. Fisheries Aquat. Sci., 106, 110-127.

Killingtviet, $\AA$ and Harby, A., 1994. Multi Purpose Planning with the River System Simulator - a decision support system for water resources planning and operation. In: Proc. First Int. Symp. Habitat Hydraulics, Norwegian Institute of Technology, Trondheim.

King, J., Brown, C. and Sabet, H., 2003. A scenario-based holistic approach to environmental flow assessments for rivers. River Res. Appl., 19, 619-639. 
King, J.M., Tharme, R.E. and de Villiers, M.S., (Eds.), 2000. Environmental flow assessments for rivers: manual for the Building Block Methodology. Water Research Commission Report TT 131/00, Pretoria, South Africa. 339pp.

Lamouroux, N. and Capra, H., 2002. Simple predictions of instream habitat model outputs for target fish populations. Freshwater Biol., 47, 1543-1556.

Lamouroux, N., Capra, H. and Pouilly, M., 1998. Predicting habitat suitability for lotic fish: linking statistical hydraulic models with multivariate habitat use models. Regul. River., 14, 1-11.

Lesotho Highlands Development Authority. 2002. Draft policy for instream flow requirements. LHDA, Maseru, Lesotho.

Matthews, R.C. and Bao, Y., 1991. The Texas Method of Preliminary Instream Flow Determination. Rivers, 2, 295-310.

Ministry of Water and Livestock Development, 2002. National Water Policy. Ministry of Water and Livestock Development, Dar Es Salaam, Tanzania.

National Research Council, 1992. Restoration of aquatic ecosystems - science technology and public policy. National Academic Press, Washington DC, USA.

Nestler, J. and Sutton, V.K., 2000. Describing scales of features in river channels using fractal geometry concepts. Regul.River. 16, 1-22.

Norris, R.H. and Thoms, M.C., 1999. What is river health? Freshwater Biol., 41, 197-209.

Parasiewicz, P., 2001. Mesohabsim: A concept for application of instream flow models in river restoration planning. Fisheries, 26, 6-13

Parasiewicz, P. and Dunbar, M.J., 2001. Physical Habitat Modelling for Fish: A developing approach. Arch. Hydrobiol. Suppl., 135, 239-268

Peters, M.R., Abt, S.R., Watson, C.C., Fischenich, J.C. and Nestler, J.M., 1995. Assessment of Restored Riverine Habitat using RCHARC. Water Resour. Bull., 31, 745-752.

Petts, G.E., Maddock, I.P., Bickerton, M. and Ferguson, A.J.D., 1995. Linking hydrology and ecology: the basis for river management. In: The ecological basis for river management, D.M.Harper and A.J.D. Ferguson (Eds.), Wiley, Chichester, UK.

Poff, N.L., Allan, J.D., Bain, M.B., Karr, J.R., Prestegaard, K. L., Richter, B.D., Sparks, R E. and Stromberg, J.C., 1997. The natural flow regime. Bioscience 47, 769-784.

Postel, S. and Carpenter, S., 1997. Freshwater ecosystem services. In: Nature's services; societal dependence on natural ecosystems, G.C. Daily (Ed.), Island Press, Washington DC., USA.

Postel, S. and Richter, B., 2003. Rivers for life; managing water for people and nature. Island Press, Washington DC, USA.

Reiser, D.W., Wesche, T.A. and Estes, C., 1989. Status of Instream Flow Legislation and Practices in North America. Fisheries, $14,22-29$

Richardson, B.A., 1996. Evaluation of instream flow methodologies for freshwater fish in New South Wales. In: Stream protection: the management of rivers for instream use I.C.Cambell (Ed.), Water Studies Centre, Chisholm Institute of Techniology, East Caulfield, NSW, Australia.

Richter, B.D., Baumgartner, J.V., Powell, J. and Braun D.P., 1996. A Method for Assessing Hydrological Alteration within Ecosystems. Conserv. Biol., 10, 1163-1174.

Richter, B.D., Baumgartner, J.V., Wigington, R. and Braun, D.P., 1997. How much water does a river need? Freshwater Biol., 37, 231-249.

Reinfelds, I., Haeusler, T., Brooks, A.J. and Williams, S. (in press). Refinement of the wetted perimeter breakpoint method for setting cease-to-pump limits and minimum environmental flow: an example from the Kangaroo River, NSW, Australia. River Res. Appl.
Rogers, K. and Bestbier, R., 1997. Development of a protocol for the definition of the desired state of riverine systems in South Africa. Department of Environmental Affairs and Tourism, Pretoria, South Africa. 100pp.

Rowlston, W.S. and Palmer, C.G., 2002. Processes in the development of resource protection provisions on South African Water Law. Proc. Int. Conf. Environmental Flows for River Systems, Cape Town, South Africa, March 2002.

Schuler, G.W. and Nehring, R.B., 1994. Using the Physical Habitat Simulation Model to evaluate a stream enhancement project. Rivers, 4, 175-193.

Sheldon, F., Thoms, M.C., Berry, O. and Puckridge, J., 2000. Using disaster to prevent catastrophe: referencing the impacts of flow changes in large dryland rivers. Regul.River. 16, 403-420.

Souchon, Y. and Keith, P., 2001, Freshwater fish habitat: science, management and conservation in France. Aquat. Ecosyst. Health Manage., 4, 401-412.

Stalnaker C.B. and Arnette J.L., 1976. Methodologies for determining instream flows for fish and other aquatic life. In: Methodologies for the determination of stream resource flow requirements: an assessment, C.B.Stalnaker and J.L. Arnette (Eds.), Utah State University, Logan, Utah. USA. 89-137.

Stewardson, M.J. and Gippel, C.J., 2003. Incorporating flow variability into environmental flow regimes using the flow events method. River Res. Appl., 19, 459-472.

Swales, S. and Harris, J.H., 1995. The Expert Panel Assessment Method (EPAM): a new tool for Determining Environmental Flows in Regulated Rivers. In: The Ecological Basis for River Management, D.M.Harper and A.J.D. Ferguson (Eds.), Wiley, Chichester, UK.

Tennant, D.L., 1976. Instream flow regimens for fish, wildlife, recreation and related environmental resources. Fisheries 1, 6-10.

Tharme, R.E., 2003. A global perspective on environmental flow assessment : emerging trends in the development and application of environmental flow methodologies for rivers. River Res. Appl., 19, 397-441.

Tharme R.E. and King J.M., 1998. Development of the building block methodology for instream flow assessments and supporting research on the effects of different magnitude flows on riverine ecosystems. Report to Water Research Commission, 576/1/98. Cape Town, South Africa.

Thoms, M.C. and Parsons, M., 2002. Eco-geomorphology: an interdisciplinary approach to river science. IAHS Publ. no. 276, 113-119.

Thoms, M.C., Sheldon, F., Roberts, J., Harris, J. and Hillman, T. J., 1996. Scientific Panel Assessment of environmental flows for the Barwon-Darling River. New South Wales Department of Land and Water Conservation, Australia.

Vehanen, T., Huusko, A., Yrjänä, T., Kylmänen, I., Sirniö, V.P. and Lahti, M., 2000. Habitat restoration in large hydropeaking impoundments in Finland: problems and solutions. In: Proc. Int. Conf: Protection and Restoration of the Environment V, V.A. Tsihrintzis, G.P. Korfiatis, K.L. Kastsifratis and A.C. Demetracopoulos, (Eds.), Thassos, Greece.

Waters, B.F., 1976. A methodology for evaluating the effects of different stream flows on salmonid habitat. In: Instream Flow Needs, J.F.Orsborn and C.H.Allman (Eds.) American Fisheries Society, Bethseda, Maryland, USA. 254-266.

Wesche, T.A. and Rechard, P.A., 1985. A summary of Instream Flow Methodologies for Fisheries and Related Research Needs. Eisenhower Consortium Bulletin, USDA Forest Service. 